Article

\title{
Rebound Effect or Induced Demand? Analyzing the Compound Dual Effects on VMT in the U.S.
}

\author{
Jihye Byun ${ }^{1}$, Sungjin Park ${ }^{2, *}$ and Kitae Jang ${ }^{1, *}$ \\ 1 The Cho Chun Shik Graduate School of Green Transportation, \\ Korea Advanced Institute of Science and Technology, Daejeon 34141, Korea; snowflower@kaist.ac.kr \\ 2 Department of Urban Design and Planning, Hongik University, Seoul 04066, Korea \\ * Correspondence: sungjin.park1@gmail.com (S.P.); kitae.jang@kaist.ac.kr (K.J.); \\ Tel.: +82-2-320-1664 (S.P.); +82-42-350-1284 (K.J.)
}

Academic Editor: Md. Kamruzzaman

Received: 1 December 2016; Accepted: 24 January 2017; Published: 7 February 2017

\begin{abstract}
This research explored the dual influence of fuel efficiency and roadway capacity on vehicle distance traveled. The empirical study was conducted by applying a generalized least square (GLS) analysis to the U.S. state-level panel data of fuel efficiency, roadway lane-miles, and vehicle miles traveled (VMT) for over three decades (1980-2010). The analysis confirmed the co-existence of rebound effect and induced demand on driving distances over the decades-improved fuel efficiency and expanded roadway capacity caused additional vehicle distance traveled, partially offsetting the benefits of the measures taken. Furthermore, the results showed that the magnitude of each effect would be unjustifiably overestimated if this dual influence was not taken into consideration.
\end{abstract}

Keywords: rebound effect; induced demand; feedback effect; fuel efficiency; road lane-mile; vehicle mile traveled

\section{Introduction}

The effort to improve personal mobility sometimes backfires with unexpected externalities that significantly undermine its initial benefit. One such well-known effect is a rebound effect, which occurs when enhanced fuel efficiency encourages more driving, offsetting the expected reduction in fuel consumption. One crucial concept defining rebound effect is travel cost. The enhanced fuel efficiency enables people to drive at lower unit cost, and thereby encourages people to drive more. In the end, the increased vehicle miles traveled (VMT) results in excess fuel consumption [1-5]. This effect has been consistently observed in various cases of improvement of energy or resource efficiency [6-8]. In previous research, the elasticity estimates-measured by the percentage change in fuel consumption in relation to the percentage change in unit-distance fuel cost-are within the range $5 \%-100 \%$ [1-19].

This rebound effect has been a dilemma for policy makers, as the expected environmental benefit turns out to be offset by increased VMT, and thus improvement in fuel efficiency could lead to environmentally harmful outcomes. However, this rebound effect may have been overestimated if it was measured separately without considering other potential causal mechanisms also influencing VMT. The most notable such effect is induced demand, which is generated when the expanded roadway capacity diminishes travel time, and in turn generates extra traffic by inducing people to travel more or by encouraging transit users to drive. This increased traffic results in excessive congestion beyond the level-of-service estimated at the planning stage of the road infrastructure expansion [20-25]. The elasticity of this effect-measured by the ratio of percentage change in vehicle distance traveled to the percentage change in roadway lane-miles-is reported to be statistically significant, although its magnitude varies across studies $[11,12,23,26]$. 
Both effects share many similarities. They work against travelers' willingness to save fuel cost or travel distance, and occur continuously over decades. As both fuel efficiency and roadway infrastructure capacity have trends that only increase, there is a possibility of overestimation if these are measured separately, and therefore the magnitudes of these effects may need to be estimated together. In most previous studies, however, they were analyzed separately $[1-5,9,10,13-16,27,28]$. Previous research was mostly done by analyzing longitudinal data at the regional (e.g., county and state) level, and by using statistical models such as time-series analysis, path analysis, and simultaneous equation models.

More recently, researchers began to conduct studies analyzing both effects together to determine their concurrent effects over the same period. Hymel et al. [11] measured both effects using U.S. state-level cross-sectional time series data (1996-2004), although a separate model was used to estimate each. As a statistical method, a three-stage least-square (3SLS) model was utilized. However, the second-order autocorrelation could not be considered using the 3SLS model; therefore, Su [12] used the lagged values of VMT for the analysis of the data collected from 2001 to 2008. Compared with the outcome of previous studies $[11,12,20,23-26]$ that used the lag term to measure lagged effect, however, the eight-year window of time may not be long enough to observe the effects of change in fuel efficiency and road infrastructure expansion, as it usually takes decades rather than years for the effects to be realized $[21,24,25]$. For more accurate and comprehensive analysis, a study needs to be done with data covering a significantly longer period. A modeling approach similar to that used by $\mathrm{Su}$ [12] was adopted for the present study, but the analysis covered a period nearly four times longer (31 years). Unlike the previous study, the present paper reports results based on real fuel efficiency data, instead of target values set by CAFE (Corporate Average Fuel Economy).

The goal of the present study involved two objectives. The first objective was to compare explanations of both rebound effect and induced demand based on economic theories. In Section 2, the two effects are explained as a function of travel time and cost, using the concept of individual utility and trip-making behavior. This section will help compare and understand the models used to estimate both effects in the following section. The second objective was to empirically analyze both effects for an extended period and to create a combined model based on it. The elasticities of the two effects are compared using a separated model and a combined model. For this purpose, data covering more than three decades (1980-2010) were collected from 50 U.S. States and the District of Columbia. Section 3 presents the analysis method. To avoid auto-correlation and heteroscedasticity issues (which are often associated with panel data), a generalized least square (GLS) model was used for the present research. Section 4 presents discussion based on the analysis results and in relation to the implications of these results for future policy.

\section{Materials and Methods}

\subsection{Economic Definitions of Rebound Effect (RE) and Induced Demand (ID)}

The common key concept defining both effects is directly related to the travel cost; therefore, the mechanisms of the two effects should be effectively explained by economic theory. An individual makes vehicle trips while consuming two major inputs: fuel and time. Hence, in previous studies [20,26,29-33], it was proposed that the distance traveled by an individual (i.e., travel amount) could be expressed by the Cobb-Douglas function of fuel and time as shown in Equation (1).

$$
D(F, T)=\alpha \times F^{\beta} \times T^{\gamma}
$$

where, $D(F, T)$ is a distance traveled by vehicles; $F$ is a fuel amount; $T$ is a travel time; and $\alpha, \beta$, and $\gamma$ are coefficients for the corresponding variables.

Figure 1 illustrates the function with a contour line connecting the set of points at which the same level of driving distance is traveled, while changing the quantities of fuels and times. The curve is presented in convex shape to show that travelers tend to reduce travel time by driving at high speed, 
thus consuming more fuel. Thus, identical cost for different combinations of fuel and time can be represented as a dotted line on the same graph, the slope of which is the ratio of fuel price, $P_{F}$, to the value of time, $P_{T}, P_{F} / P_{T}$.

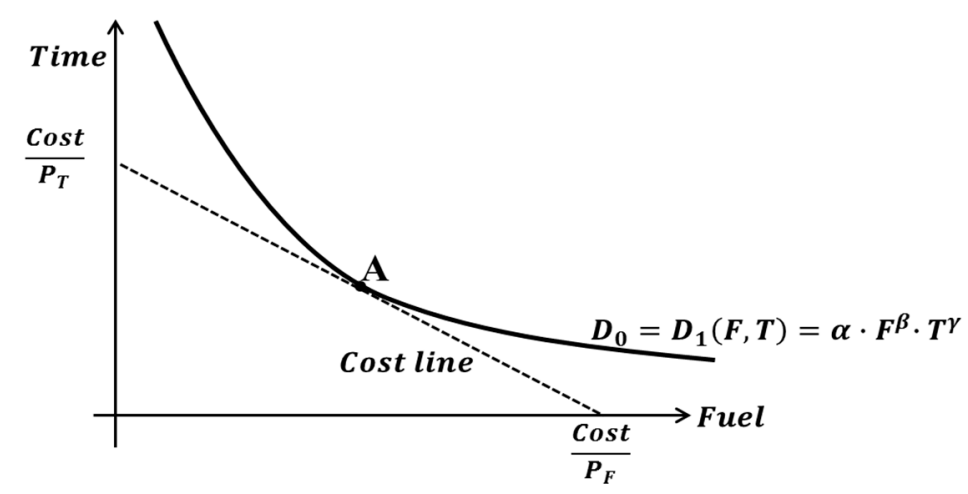

Figure 1. Time, Energy, Travel Distance, Cost line, and Equilibrium.

The level of fuel and time consumption is determined where the cost line is tangential to the curve, $D(F, T)$, as individual travelers make input choices to minimize the cost for a driving distance. This equilibrium point moves as changes occur in trip-making process, $D(F, T)$, or prices, $P_{F}$ or $P_{T}$.

\subsubsection{Rebound Effect: Individual Behavior When Fuel Efficiency Improves}

When fuel efficiency improves, people can drive the same distance $D_{0}$ with less fuel consumption. If the fuel savings is $\mathrm{x}$, the curve $D_{1}(F, T)=D_{0}$ is shifted by the amount of $\mathrm{x}$ as shown in Figure 2, and the shifted function is as follows: $D_{2}(F, T)=D_{1}(F-x, T)=D_{0}$. As a result, the equilibrium point moves from point $A$ to $B$. This means that fuel cost per unit travel distance diminishes. Hence, individual travelers now perceive the current value of time per distance to be relatively expensive, and therefore are willing to substitute time for fuel (i.e., spend more fuel to save time), shifting the curve to $D_{3}(F, T)=D_{0}$. Because vehicles consume more fuel to increase speed by an equal amount in a high-speed range than in a low-speed range [34,35], the amount of shift is greater when fuel consumption is small. This sequence explains the rebound effect (RE) in the short run, with which energy use increases and travel time decreases more than the level expected for the same travel distance. The short-run RE is measured by the horizontal distance between points B and C.

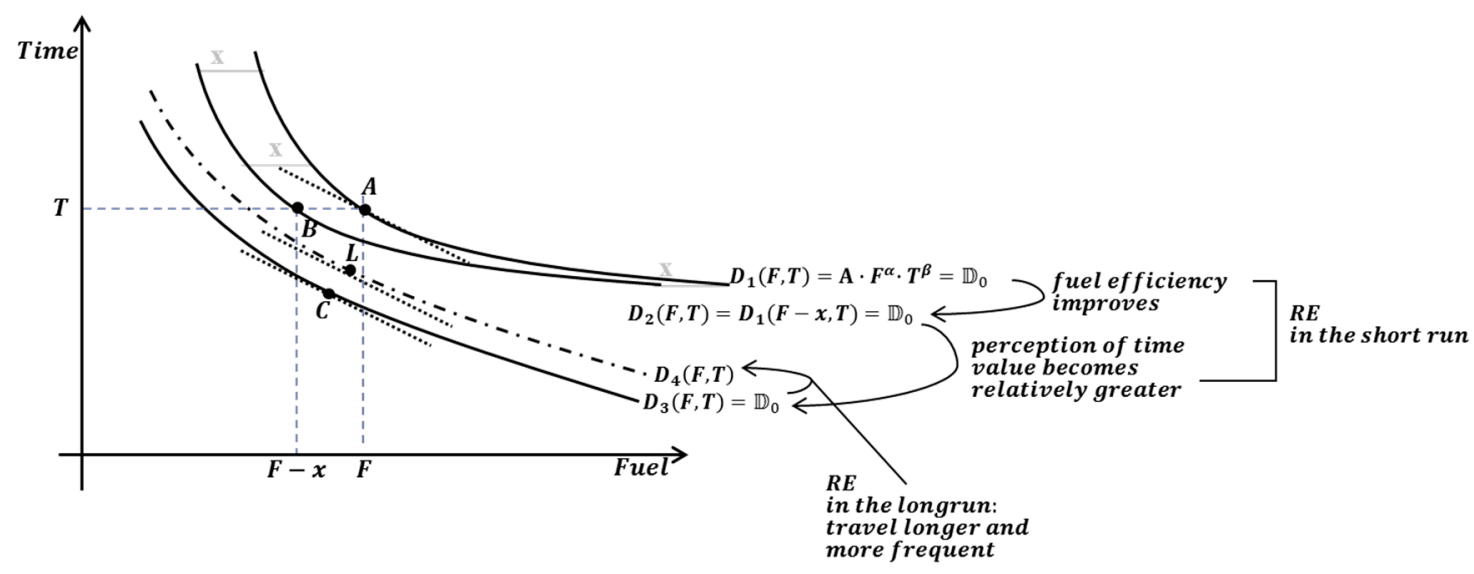

Figure 2. Short- and long-run rebound effects change of time and energy usage in relation to travel distance. 
The efficiency improvement eventually reduces overall driving cost by encouraging people to drive more frequently and longer [36-38] or by making a modal shift from public transit [39-41]. This process takes place for an extended time, shifting the curve further outward, $D_{4}(F, T)>D_{0}$, and resulting in the long-run $R E[42,43]$. This long-run $R E$ is expedited, as the reduction in driving cost increases purchasing power [3] and enables people to invest in more fuel-efficient vehicles.

\subsubsection{Induced Demand: Individual Behavior When the Road Capacity Increases}

Roadway expansion to increase capacity reduces travel time by relieving traffic congestion, and thereby triggers a process similar to the one caused by RE, but working in an opposite direction. Suppose that the amount of travel time saved by the newly added road capacity is $y$. Then, the function of distance traveled shifts to $D_{5}(F, T)=D_{1}(F, T-y)=D_{0}$, and the equilibrium point moves from point $A$ to $G$ (Figure 3). Consequently, an individual traveler perceives the value of travel time per distance to be relatively less expensive compared to the fuel price. This encourages substitution of fuel for time (i.e., spend more time to save fuel), further shifting the curve to $D_{6}(F, T)=D_{0}$, and encourages changing the travel route to take advantage of the road with newly added capacity. This process induces more travel demand for the roadway network than expected at the planning stage. However, this induced demand (ID) crowds the roadway, and therefore a trip for the same travel distance requires more time and fuel, shifting $D_{6}(F, T)$ to $D_{7}(F, T)=D_{0}$. This phenomenon is the ID in the short run, with which travel time increases and energy use decreases more than the level expected for the same travel distance. Along with route changes and modal shifts, it is also reported that roadway expansion changes land use patterns, attracting more residents to live along the expanded roadway [26]. This is the crux of the transport-related impact of urban sprawl or suburbanization, a well-known phenomenon in urban planning which is most commonly observed in the fast-growing U.S. metropolitan areas. As a result, people tend to move out further along the new or expanded highways, drive longer distances, and make more trips. This increased travel often induces congestion and results in travel delays. This long-run ID further shifts the curve outward to $D_{8}(F, T)>D_{0}$.

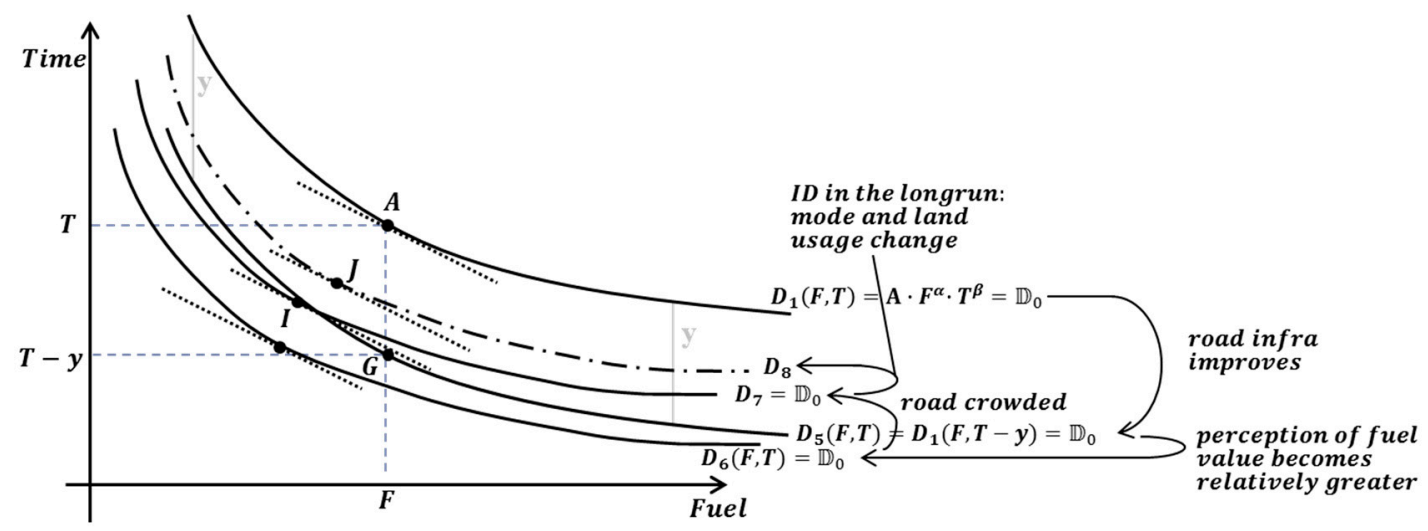

Figure 3. Short- and long-run induced demand (ID) effects: change of time and energy usage in relation to travel distance.

\subsection{Data Description}

To evaluate the dual influences of changes in fuel efficiency and roadway capacity on travel distance, this study used unbalanced panel (cross-sectional time-series) data from 50 states and one district in the U.S. covering 31 years (1980-2010). Vehicle-miles traveled (VMT) data for each state were collected as an outcome variable. Fuel efficiency was estimated by dividing statewide fuel consumption by VMT, which is the procedure used by the EIA (U.S. Energy Information Administration). Roadway lane-miles were used to represent roadway capacity, as in previous research [44-48]. Table 1 shows the description of all the data collected for the research, including those to be tested as possible influential 
factors, such as gross domestic product (GDP), energy price, per capita income, population, and the number of registered vehicles. The data was collected for each of 51 states (including the District of Columbia) every year from 1980 to 2010 (31 years). Therefore, the mean and standard deviation of each variable in Table 1 are calculated based on the 1581 samples extracted from the 51 panels during the 31 years.

Table 1. Characteristics of the variables use in this study.

\begin{tabular}{|c|c|c|c|c|c|c|}
\hline \multicolumn{2}{|c|}{ Variables } & \multirow{2}{*}{$\begin{array}{c}\text { Description } \\
\text { Statewide Total } \\
\text { Distance Traveled by } \\
\text { Vehicles }\end{array}$} & \multirow{2}{*}{$\begin{array}{c}\text { Unit } \\
10^{9} \text { Vehicle-miles }\end{array}$} & \multirow{2}{*}{$\begin{array}{c}\text { Mean } \\
46.74\end{array}$} & \multirow{2}{*}{$\begin{array}{l}\text { STD } \\
50.39\end{array}$} & \multirow{2}{*}{$\begin{array}{c}\text { Sources } \\
\begin{array}{c}\text { U.S. Highway Statistics [49] } \\
\text { (Table VM-2) }\end{array}\end{array}$} \\
\hline $\begin{array}{l}\text { Dependent } \\
\text { Variables }\end{array}$ & VMT & & & & & \\
\hline \multirow{7}{*}{$\begin{array}{l}\text { Explanatory } \\
\text { Variables }\end{array}$} & Lane-Miles & $\begin{array}{c}\text { Roadway Lane-Miles } \\
\text { that Approximately } \\
\text { Measure Roadway } \\
\text { Capacity }\end{array}$ & $10^{4}$ Lane-miles & 16.06 & 10.90 & $\begin{array}{l}\text { U.S. Highway Statistics [49] } \\
\text { (Table HM-60) }\end{array}$ \\
\hline & $\begin{array}{c}\text { Fuel } \\
\text { Efficiency }\end{array}$ & $\begin{array}{c}\text { Vehicle Mile Traveled } \\
\text { per Fuel } \\
\text { Consumption }\end{array}$ & Mile/gallon & 15.58 & 2.11 & $\begin{array}{l}\text { U.S. Highway Statistics [49] } \\
\text { (Table MF-21 And VM-2) }\end{array}$ \\
\hline & GDP & $\begin{array}{c}\text { Gross Domestic } \\
\text { Product by State } \\
\text { (converted to } 10^{10} \$ \text { of } \\
\text { year } 2011 \text { value) }\end{array}$ & $10^{10} \$$ & 15.69 & 21.81 & U.S. Census Bureau [50] \\
\hline & Energy Price & $\begin{array}{l}\text { The Price of Motor } \\
\text { Gasoline Petroleum }\end{array}$ & Dollars $/ 10^{6} \mathrm{Btu}$ & 11.81 & 4.98 & IEA [51] (Table ET2) \\
\hline & $\begin{array}{l}\text { Per Capita } \\
\text { Income }^{1}\end{array}$ & $\begin{array}{l}\text { Per Capita Personal } \\
\text { Income by State }\end{array}$ & $10^{3} \$$ & 23.75 & 9.97 & $\begin{array}{c}\text { U.S. Bureau of Economic } \\
\text { Analysis [52] and Bureau of } \\
\text { the Census [50] }\end{array}$ \\
\hline & Population $^{1}$ & $\begin{array}{l}\text { Number of Residents } \\
\text { in State }\end{array}$ & $10^{6}$ People & 52.30 & 58.01 & $\begin{array}{l}\text { U.S. Bureau of the Census } \\
\text { [50] (Table 1) }\end{array}$ \\
\hline & $\begin{array}{l}\text { Number of } \\
\text { Vehicles }{ }^{1}\end{array}$ & $\begin{array}{c}\text { Motor-Vehicles } \\
\text { Registered by State }\end{array}$ & $10^{8}$ Vehicles & 41.03 & 45.09 & $\begin{array}{l}\text { U.S. Highway Statistics [49] } \\
\text { (Table MV-1) }\end{array}$ \\
\hline
\end{tabular}

${ }^{1}$ Excluded due to the multicollinearity issue. GDP: gross domestic product; IEA: International Energy Agency; VMT: vehicle miles traveled.

Pearson correlation coefficients were evaluated for a possible correlation among the variables. The test results showed that per capita income and population are highly correlated with GDP, and that the number of vehicles is correlated with VMT. To avoid multicollinearity among variables, per capita income, population, and the number of vehicles were excluded from the estimations by models.

Panel data commonly have two potential issues that violate the assumptions on error terms of ordinary least squares (OLS). First, the data collected from the same state are auto-correlated over time, so the estimated coefficients often over-represent the relationship between independent and outcome variables (i.e., auto-correlation). Second, the variances of the data across states are unequal (i.e., heteroscedasticity). To examine auto-correlation and heteroscedasticity, we performed two widely-used statistical tests: Durbin-Watson and White heteroscedasticity, respectively (see more details in Greene [31]). The test results indicate that the data from 45 states (out of 51 states and district) are auto-correlated at the $5 \%$ significance level, and that variances for different states are unequal at the $5 \%$ significance level.

\section{Results}

Generalized Least Square was chosen to avoid the possible auto-correlation and heteroscedasticity issues often associated with panel data [31].

$$
Y=X B+\varepsilon
$$


Those factors of the equation are vectors: for $\mathrm{n}$ subjects, the $Y$ is $n \times 1$ matrix of dependent variable, $X$ is $n \times k$ matrix of $k$ independent variables, is $n \times k$ matrix of coefficients, and $\varepsilon$ is $n \times 1$ matrix of error terms. In OLS, the coefficient matrix is estimated by $\hat{B}_{O L S}=(X / X)^{-1} X / Y$. In GLS, the $B$ can be estimated by relaxing the assumption that $\varepsilon$ has equal variance, $E[\varepsilon \mathcal{E} / X]=\sigma^{2} I$, where $I$ is the identity matrix. Thus, $\hat{B}_{G L S}=\left(X / \Omega^{-1} X\right)^{-1} X / \Omega^{-1} Y$, where $\Omega$ is a disturbance term and $E[\varepsilon \varepsilon / X]=\sigma^{2} \Omega$, so that the autocorrelation and unequal variances can be reflected by applying proper $\Omega$. Because our data have $m$ panels with $t$ time steps each, we generalized [53] the error term as $\varepsilon_{i t}=\rho_{i} \varepsilon_{i(t-1)}+u_{i t}$ and

$$
\begin{aligned}
E\left[\varepsilon \mathcal{E}{ }^{\prime} X\right] & =\sigma^{2} \Omega \\
& =\Sigma_{m \times m} \otimes \Pi_{t \times t}
\end{aligned}
$$

where $\Sigma_{m \times m}=\left[\begin{array}{cccc}\sigma_{1}^{2} & 0 & \cdots & 0 \\ 0 & \sigma_{2}^{2} & \cdots & 0 \\ \vdots & \vdots & \ddots & \vdots \\ 0 & 0 & \cdots & \sigma_{m}^{2}\end{array}\right], \Pi_{t \times t}=\left[\begin{array}{ccccc}1 & \rho & \rho^{2} & \cdots & \rho^{t-1} \\ \rho & 1 & \rho & \cdots & \rho^{t-2} \\ \vdots & \vdots & \vdots & \ddots & \vdots \\ \rho^{t-1} & \rho^{t-2} & \rho^{t-3} & \cdots & 1\end{array}\right], \sigma_{i}^{2}=\frac{\sigma_{i u}^{2}}{1-\rho_{i}}$, where $\rho$ is an autocorrelation coefficient, $i$ is the panel identification from " 1 " to $m$, and $u$ is the error of the autocorrelation equation. To examine the dual influences of energy efficiency (RE) and road lane-miles (ID) on travel distance, three regression equations were formulated to express VMT as a function of energy efficiency, lane miles, or both, in a logarithm format. Lagged variables were also tested, because the effects of changes in energy efficiency and lane miles often take a significant amount of time to be realized [26]. GDP and energy price were added as control variables.

- $\quad$ Model 1 (RE effect only): $\ln \left(V M T_{t}\right)=\alpha_{1} \ln \left(E F_{t}\right)+\alpha_{2} \ln \left(E F_{t-1}\right)+\alpha_{3} \ln \left(G D P_{t}\right)+\alpha_{4} \ln \left(E P_{t}\right)+\epsilon_{\alpha}$

- Model 2 (Induced demand only): $\ln \left(V M T_{t}\right)=\beta_{1} \ln \left(L M_{t}\right)+\beta_{2} \ln \left(L M_{t-1}\right)+\beta_{3} \ln \left(L M_{t-2}\right)+$ $\beta_{4} \ln \left(L M_{t-3}\right)+\beta_{5} \ln \left(G D P_{t}\right)+\beta_{6} \ln \left(E P_{t}\right)+\epsilon_{\beta}$.

- $\quad$ Model 3 (Dual effects-RE and ID): $\ln \left(V M T_{t}\right)=\gamma_{1} \ln \left(E F_{t}\right)+\gamma_{2} \ln \left(E F_{t-1}\right)+\gamma_{3} \ln \left(L M_{t}\right)+$ $\gamma_{4} \ln \left(L M_{t-1}\right)+\gamma_{5} \ln \left(L M_{t-2}\right)+\gamma_{6} \ln \left(L M_{t-3}\right)+\gamma_{7} \ln \left(G D P_{t}\right)+\gamma_{8} \ln \left(E P_{t}\right)+\epsilon_{\gamma}$

The coefficients estimated using the three models are presented in Table 2. Since Model 1 includes energy efficiency only, the estimated coefficients corresponding to energy efficiency, $\alpha_{1}$ and $\alpha_{2}$, represent the effect of change in energy efficiency on VMT, without reflecting the effect of change in lane miles. The sign of $\alpha_{1}$ shows that energy efficiency is positively correlated to VMT, and based on its coefficient, it is inferred that $69.9 \%$ change in VMT is expected for each $1 \%$ change in energy efficiency. This effect is expected to diminish for the lagged year, as the estimated coefficient for the lagged year variable $\alpha_{2}$ is only 0.119 . This indicates that the effect from a change in energy efficiency is nearly instant, rather than delayed.

Table 2. Coefficients of each scenario.

\begin{tabular}{cccc}
\hline \multirow{2}{*}{ Variables/Model } & \multicolumn{3}{c}{ Dependent Variable Is Log of Total VMT } \\
\cline { 2 - 4 } & Model 1 (Only RE) & Model 2 (Only ID) & Model 3 (RE \& ID) \\
\hline Energy Efficiency & $0.6989(0.000)$ & - & $0.4594^{1}(0.000)$ \\
Energy Efficiency (1 year lag) & $0.1191(0.000)$ & - & $0.0546(0.000)$ \\
Lane-Miles & - & $0.2832(0.000)$ & $0.1555(0.000)$ \\
Lane-Miles (1 year lag) & - & $0.2071(0.000)$ & $0.1198(0.001)$ \\
Lane-Miles (2 year lag) & - & $0.1886(0.000)$ & $0.0874(0.011)$ \\
Lane-Miles (3 year lag) & - & $0.1584(0.000)$ & $0.0866(0.006)$ \\
GDP & $0.6827(0.000)$ & $0.5781(0.000)$ & $0.5421(0.000)$ \\
Energy Price & $-0.0922(0.000)$ & $-0.0190(0.002)$ & $-0.0891(0.000)$ \\
\hline
\end{tabular}

Note that the numbers in parentheses are $p$-values. ${ }^{1}$ Previous studies that separately estimated the elasticities of rebound effect and induced demand have reported widely-varying outcomes: $5 \%-100 \%$ elasticity for rebound effect [1-19] and $10 \%-60 \%$ for induced demand $[20-26,28]$. These values are relatively high compared with the estimations made by this study: $45.9 \%$ elasticity for rebound effect and $15.6 \%$ elasticity for induced demand. However, it is difficult to directly compare those results, mainly because they are conducted under different hypotheses, research designs, and data collecting methodologies. 
Model 2 estimates the coefficient of change in lane-miles without considering energy efficiency. The estimated coefficient, $\beta_{1}$, is 0.2832 , indicating that each $1 \%$ change in lane-miles is associated with a $0.2832 \%$ change in VMT. For Model 2 , lagged variables were also tested to examine the possibility of delayed effects from the change in lane miles on VMT. Three short-term lagged-lane-mile variables enter the model at the statistically significant level. Models also use variables with four or more year-lagged effects for their estimations, but in such cases, the $p$-values are substantially lower. This is consistent with the previous findings that the use of two to four lagged-year variables improved the model performance [46]. Judging based on the magnitudes of the lagged-year coefficients $\left(\beta_{2}>\beta_{3}>\beta_{4}\right)$, it can be inferred that the lagged effect on VMT gradually decreases from the second year to the fourth.

For Model 3, both RE and ID effects were tested. Two RE and four ID variables, along with GDP and energy price enter the model at the statistically significant level. The fitness of the model was measured using a pseudo R-square value $[28,54,55]$. The value was fairly high at 0.966 for Model 3 . The coefficient of each variable is smaller for Model 3 than for the two other models. The elasticity of the energy efficiency of Model $1 \alpha_{1}$ is $52.13 \%$ greater than Model $3 \gamma_{1}$, and the elasticity of lane miles of Model $2 \beta_{1}$, is $82.12 \%$ greater than Model $3 \gamma_{3}$. This result confirms the research hypothesis that the effects of RE and ID could be overestimated if estimation is made separately. Because the estimated coefficients measure the percentage change in VMT with percent change in corresponding variables, we can also estimate the relative effects of RE and ID on the increase in VMT. In the U.S. over the last twelve years (1999-2010), average energy efficiency increased annually by $1.9 \%$ on average, and total lane-miles was extended by $3.8 \%$ on average, which in the forms of RE and ID, account for rises in VMT of $6.0 \%$ and $7.5 \%$, respectively.

\section{Discussion and Conclusions}

Most past studies have separately dealt with either rebound effect or induced demand, although in reality they may be closely interconnected. Based on the U.S. data collected for the 31-year span (1980-2010), we analyzed the hitherto rarely explored joint impact of the two phenomena, and compare their relative influences on VMT at the macro level. When rebound effect and induced demand were evaluated separately using Models 1 and 2, the amounts of rebound effect and induced demand on VMT increase would be $9.1 \%$ and $10.7 \%$, respectively. Meanwhile, the joint model (Model 3) reveals that rebound effect and induced demand account for $6.0 \%$ and $7.5 \%$ of the VMT increase during the time span, and proves that the impact of one of them can be easily overestimated if tested separately without considering the impact of the other.

For future transportation-energy policies, it is important to accurately measure the long-term social and environmental benefits of improvement in fuel efficiency. The world dependency on fossil fuels has been one of the most urgent issues to be tackled by our global civilization. In June 2015, G7 leaders announced a stunning and arguably ambitious green statement in which they agreed to phase out fossil fuels by 2100 [56]. Although controversy lingers over whether this zero fossil fuel target is achievable, it successfully sends a clear message that the direction of future energy policy involves two major objectives: renewable energy and fuel efficiency. Transportation energy policy is very important in the U.S., given that energy consumption for transportation is $28 \%$ of total U.S. energy use [57] and that transportation accounts for $32.9 \%$ of $\mathrm{CO}_{2}$ emission in the U.S. (International Energy Agency (IEA), 2014). The situation is even worse when it comes to petroleum use, as transportation is responsible for $67 \%$ of the total petroleum consumption in the U.S. [57].

In this context, future improvements in fuel efficiency should be critical, not only for individual travelers, but also for society as a whole. Even so, the related social benefit expected has been questioned by the claim that a significant amount of energy saving is offset by a rebound effect. However, the findings of the present study suggest that the impact of induced demand on VMT is similar to that of the rebound effect, perhaps even slightly higher for the last decade; therefore, the 
magnitude of the environmentally negative rebound effect may have been overestimated. If true, the social benefit expected from improved fuel efficiency has been unjustifiably discounted.

To verify the findings of this research, studies need to be conducted with more control variables and finer measurement units. With various income variables such as discretionary and real income, for example, a household-level micro-analysis may deepen the understanding of this complicated dual effect. It would also be great to have a new research design and statistical tool that could be more effective for measuring the relative influence of each determinant. With this, we could tell what percentage of the increase in VMT is caused by rebound effect alone, excluding the influence of induced demand or other interferential factors. Another drawback of this study is its inability to consider the speed factor for measuring rebound effects. As proven by Galvin (2016), increased speed and acceleration - the expected change in driving behavior resulting from increased energy efficiency - need to be considered when calculating the rebound effect-especially tested on VMT [58]. With a macro research design, however, our study has a limitation to accurately measure drivers' behavioral change solely caused by increased fuel efficiency. Drivers in heavily urbanized areas cannot often speed up at their will, mainly due to traffic congestion, which has been increased in the U.S. for various reasons. To fully take the speed rebound effect into consideration, future research may need to explore the possibility of utilizing a mixed method by adding micro simulation approaches similar to the one adopted by Galvin (2016).

Acknowledgments: This research was supported by the National Research Foundation of Korea grant funded by the Korea government (MSIP) (NRF-2014R1A2A1A11052725).

Author Contributions: Jihye Byun, Sungjin Park and Kiate Jang conceived and designed the research; Jihye Byun conducted the research and drafted the manuscript. Sungjin Park revised the manuscript and Kitae Jang supervised the overall work. All authors read and approved the final manuscript.

Conflicts of Interest: The authors declare no conflict of interest.

\section{References}

1. Goldberg, P.K. The effects of the corporate average fuel efficiency standards in the US. J. Ind. Econ. 1998, 46, 1-33. [CrossRef]

2. Greene, D.L.; Kahn, J.R.; Gibson, R.C. Fuel economy rebound effect for U.S. household vehicles. Energy J. 1999, 20, 1-31. [CrossRef]

3. Berkhout, P.H.; Muskens, J.C.; Velthuijsen, J.W. Defining the rebound effect. Energy Policy 2000, 28, 425-432. [CrossRef]

4. Birol, F.; Keppler, J.H. Prices, technology development and the rebound effect. Energy Policy 2000, 28, 457-469. [CrossRef]

5. Sorrell, S.; Dimitropoulos, J. The rebound effect: Microeconomic definitions, limitations and extensions. Ecol. Econ. 2008, 65, 636-649. [CrossRef]

6. Grepperud, S.; Rasmussen, I. A general equilibrium assessment of rebound effects. Energy Econ. 2004, 26, 261-282. [CrossRef]

7. Hertwich, E.G. Consumption and the rebound effect: An industrial ecology perspective. J. Ind. Ecol. 2008, 9, 85-98. [CrossRef]

8. Wei, T. A general equilibrium view of global rebound effects. Energy Econ. 2010, 32, 661-672. [CrossRef]

9. Greene, D.L. Vehicle use and fuel economy: How big is the "rebound" effect? Energy J. 1992, 13, 117-143. [CrossRef]

10. Small, K.A.; van Dender, K. The Effect of Improved Fuel Economy on Vehicle Miles Traveled: Estimating the Rebound Effect Using U.S. State Data, 1966-2001; University of California Energy Institute: Berkeley, CA, USA, 2005.

11. Hymel, K.M.; Small, K.A.; Dender, K.V. Induced demand and rebound effects in road transport. Transp. Res. B Methodol. 2010, 44, 1220-1241. [CrossRef]

12. Su, Q. Induced motor vehicle travel from improved fuel efficiency and road expansion. Energy Policy 2011, 39, 7257-7264. [CrossRef]

13. Hann, P.; Mueller, M.G.; Peters, A. Does the hybrid Toyota Prius lead to rebound effects? Analysis of size and number of cars previously owned by Swiss Prius buyers. Ecol. Econ. 2006, 58, 592-605. [CrossRef] 
14. Sorrel, S.; Dimitropoulos, J.; Sommerville, M. Empirical estimates of the direct rebound effect: A review. Energy Policy 2009, 37, 1356-1371. [CrossRef]

15. Small, K.A.; van Dender, K. Fuel efficiency and motor vehicle travel: The declining rebound effect. Energy J. 2007, 28, 25-51. [CrossRef]

16. Roy, J. The rebound effect: Some empirical evidence from India. Energy Policy 2000, 28, 433-438. [CrossRef]

17. Moshiri, S.; Aliyev, K. Rebound effect of efficiency improvement in passenger cars on gasoline consumption in Canada. Ecol. Econ. 2017, 131, 330-341. [CrossRef]

18. Odeck, J.; Johansen, K. Elasticities of fuel and traffic demand and the direct rebound effects: An econometric estimation in the case of Norway. Transp. Res. A Policy Pract. 2016, 83, 1-13. [CrossRef]

19. Zhang, Y.J.; Peng, H.R.; Liu, Z.; Tan, W. Direct energy rebound effect for road passenger transport in China: A dynamic panel quantile regression approach. Energy Policy 2015, 87, 303-313. [CrossRef]

20. Goodwin, P.; Unit, T.S. Empirical evidence on induced traffic: A review and synthesis. Transportation 1995, 23, 35-54. [CrossRef]

21. Hills, P.J. What is induced traffic? Transportation 1996, 23, 5-16. [CrossRef]

22. Abelson, P.W.; Hensher, D.A. Induced travel and user benefit: Clarifying definitions and measurement for urban road infrastructure. In Handbook of Transport Systems and Traffic Control, 1st ed.; Kenneth, J.B., David, A.H., Eds.; Elsevier Science: Amsterdam, The Netherlands, 2001; pp. 125-141.

23. Cervero, R. Road expansion, urban growth, and induced travel: A path analysis. J. Am. Plan. Assoc. 2003, 69, 145-163. [CrossRef]

24. Noland, R.B. Transport planning and environmental assessment: Implications of induced travel effects. Int. J. Sustain. Transp. 2007, 1, 1-28. [CrossRef]

25. Litman, T. Generated traffic and induced travel implications for transport planning. Inst. Transp. Eng. 2004, 71, 38-47.

26. Noland, R.B. Relationships between highway capacity and induced vehicle travel. Transp. Res. A Policy Pract. 2001, 35, 47-72. [CrossRef]

27. Binswanger, M. Technological progress and sustainable development: What about the rebound effect? Ecol. Econ. 2001, 36, 119-132. [CrossRef]

28. Noland, R.B.; Cowart, W.A. Analysis of metropolitan highway capacity and the growth in vehicle miles of travel. Transportation 2000, 27, 363-390. [CrossRef]

29. Frohlich, P. Induced traffic: Review of the explanatory models. In Proceedings of the 3rd Swiss Transport Research Conference, Ascona, Switzerland, 19-21 March 2003.

30. Goodwin, P.; Dargay, J.; Hanly, M. Elasticities of road traffic and fuel consumption with respect to price and income: A review. Transp. Rev. 2013, 24, 275-292. [CrossRef]

31. Greene, W.H. Econometric Analysis, 7th ed.; Pearson: London, UK, 2011.

32. Linn, J. The Rebound Effect for Passenger Vehicles. Resources for the Future Discussion Paper No. 13-19. 2013. Available online: http:/ /dx.doi.org/10.2139/ssrn.2292007 (accessed on 29 July 2015).

33. Strathman, J.G.; Dueker, K.J.; Sanchez, T.; Zhang, J.; Riis, A.E. Analysis of Induced Travel in the 1995 NPTS; Center for Urban Studies, Portland State University: Portland, OR, USA, 2000.

34. Rouwendal, J. An economic analysis of fuel use per kilometre by private cars. J. Transp. Econ. Policy 1996, 30, 3-14.

35. Chang, D.J.; Morlok, E.K. Vehicle speed profiles to minimize work and fuel consumption. J. Transp. Eng. 2005, 131, 173-182. [CrossRef]

36. Englin, J.; Cameron, T.A. Augmenting travel cost models with contingent behavior data. Environ. Resour. Econ. 1996, 7, 133-147. [CrossRef]

37. Smith, V.K.; Kopp, R.J. The spatial limits of the travel cost recreational demand model. Land Econ. 1980, 56, 64-72. [CrossRef]

38. McKean, J.R.; Johnson, D.M.; Walsh, R.G. Valuing time in travel cost demand analysis: An empirical investigation. Land Econ. 1995, 71, 96-105. [CrossRef]

39. McFadden, D. The measurement of urban travel demand. J. Public Econ. 1974, 3, 303-328. [CrossRef]

40. Mogridge, M.J.H. Strategic population forecasting for a conurbation using the negative exponential density model. Transp. Res. A Gen. 1985, 19, 189-206. [CrossRef]

41. Nurdden, A.; Rahmat, R.; Ismail, A. Effect of transportation policies on modal shift from private car to public transport in Malaysia. J. Appl. Sci. 2007, 7, 1013-1018. 
42. Dahl, C.A. Gasoline demand survey. Energy J. 1986, 7, 67-82. [CrossRef]

43. Southworth, F. VMT Forecasting for National Highway Planning: A Review of Existing Approaches; Office of Policy Development, Federal Highway Administration: Washington, DC, USA, 1986.

44. Koppelman, F.S. Preliminary Study for Development of a Macro Urban Travel Demand Model; No. DOT-P-5010.1; U.S. Department of Transportation: Washington, DC, USA, 1972.

45. Payne-Maxie Consultants, Blayney-Dyett and Urban and Regional Planners. The Land Use and urban Development Impacts of Beltways Final Report; No. DOT-OS-90079; U.S. Department of Housing and Urban Development: Washington, DC, USA, 1980.

46. Hansen, M.; Huang, Y. Road supply and traffic in California urban areas. Transp. Res. A Policy Pract. 1997, 31, 205-218. [CrossRef]

47. Fulton, L.M.; Noland, R.B.; Meszler, D.J.; Thomas, J.V. A statistical analysis of induced travel effects in the U.S. mid-Atlantic region. J. Transp. Stat. 2000, 3, 1-14.

48. Cervero, R.; Hansen, M. Induced travel demand and induced road investment: A simultaneous equation analysis. J. Transp. Econ. Policy 2002, 36, 469-490.

49. Federal Highway Administration (1980-2010) Highway Statistics Series. Available online: http://www. fhwa.dot.gov/policyinformation/statistics.cfm (accessed on 6 March 2014).

50. U.S. Bureau of the Census, Population Estimates and Population Distribution Branches; Census and Preliminary Estimates of the Intercensal Population of the US and States. Release Date: December 2011. Available online: https://development.ohio.gov/files/research/P100000007.pdf (accessed on 6 March 2014).

51. International Energy Agency (IEA). $\mathrm{CO}_{2}$ Emissions from Fuel Combustion-Highlights; IEA: Paris, France, 2014.

52. U.S. Energy Information Administration. State Energy Data System (SEDS): 1960-2010; U.S. Energy Information Administration: Washington, DC, USA, 2010.

53. Chen, X.; Lin, S.; Reed, W.R. A Monte Carlo evaluation of the efficiency of the PCSE estimator. Appl. Econ. Lett. 2008, 17, 7-10. [CrossRef]

54. Buse, A. Goodness of fit in generalized least squares estimation. Am. Stat. 1973, 27, 106-108. [CrossRef]

55. Theil, H. Economic Forecasts and Policy, 2nd ed.; North Holland Publishing Co.: Amsterdam, The Netherlands, 1961.

56. The Guardian. Available online: https://www.theguardian.com/environment/2015/jun/08/g7-fossil-fuelpledge-is-a-diplomatic-coup-for-germanys-climate-chancellor (accessed on 10 August 2015).

57. Davis, S.; Diegel, S.; Boundy, R. Transportation Energy Data Book, 33rd ed.; Prepared by Oak Ridge National Laboratory and Roltek, Inc. for the U.S. Department of Energy; Oak Ridge National Laboratory: Oak Ridge, TN, USA, 2014.

58. Galvin, R. Rebound effects from speed and acceleration in electric and internal combustion engine cars: An empirical and conceptual investigation. Appl. Energy 2016, 172, 207-216. [CrossRef]

(C) 2017 by the authors; licensee MDPI, Basel, Switzerland. This article is an open access article distributed under the terms and conditions of the Creative Commons Attribution (CC BY) license (http:/ / creativecommons.org/licenses/by/4.0/). 